\title{
Reshuffling of funding councils jeopardizes plans for UK academic computer network
}

London. The forthcoming realignment of Britain's higher education funding councils into four regional bodies has thrown a wrench into the works for plans to develop Super JANET, a successor to the existing British academic computer network.

Super JANET is a high band-width optical fibre network capable of sending information at a rate of gigabits a second - a thousand times faster than JANET. Whereas JANET is capable of carrying data, text files and electronic mail, Super JANET will allow distributed computing, transfer of still and moving images, interactive use of computers and immediate visual representation of data and the remote use of computers with differing architectures for single tasks. As such, Super JANET is expected to improve access to computing facilities, reducing delays and reversing the trend of some researchers being forced to work overseas to obtain access to more powerful US networks.

The Universities Funding Council (UFC) has promised to spend $£ 20$ million (US $\$ 35$ million) to develop Super JANET between 1993 and 1996. But from April next year, responsibility for funding higher education moves from it and the Polytechnics and Colleges Funding Council (PCFC) to four regional funding councils, covering England, Wales, Scotland and Northern Ireland. The dissolution of the UFC means that plans for Super JANET must be renegotiated with the new funding bodies.

Also at stake is the future management structure of British academic networks. There is a proposal to transfer, by April 1993,
JANET and Super JANET from the funding council's Information Systems Committee (ISC) to the UK Education and Research Networking Association (UKERNA), an independent body with the nonprofit-making status of a scientific research association. The networking association will draw funds from the new higher education funding bodies, the research councils and possibly the Department of Trade and Industry.

However, the people behind UKERNA are having trouble convincing the Department For Education to provide them with funding, and they are worried that UKERNA may be left out of the hierarchy if the situation is not resolved before the funding systems change. Although the department apparently supports the UKERNA proposal, its civil servants have tied the elected management in a seemingly endless cycle of question-and-answer over the last six months. UKERNA hopes to break this deadlock with a report from an independent consultant on UKERNA's policy, plans and possible contribution to be submitted to the department and to Treasury by November.

In the interim, the association will spend the rest of the $£ 5$ million it was allocated in 1992 to hire a contractor to set up a pilot network. The aim is to secure additional funding by demonstrating real applications to ministers in early 1993. If the money is not forthcoming this year, attempts will be made to keep the project alive until 1994.

UKERNA would also like to set up a trading company that enables industrial companies to tap into JANET and, eventually,

\section{Japanese moth collection lands in London}

The Natural History Museum in London has taken delivery of 200,000 moth specimens in a bequest from the Japanese entomologist Hiroshi Inoue (right). The collection, which includes more than 500 holotype specimens (the basis of initial species classification), is the result of nearly half a century of field work in Japan, Taiwan and Nepal. Inoue wanted the collection moved before his death from its present home in Otsuma Women's University, Saitama Prefecture, so that he could continue to work on

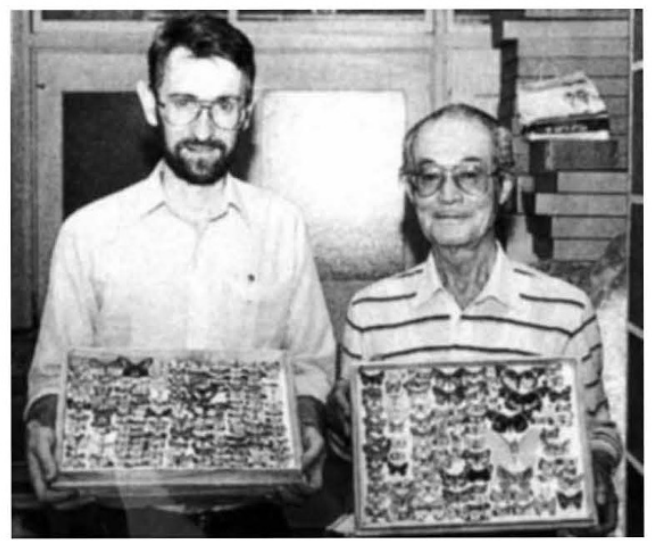

it in collaboration with museum entomologists. Malcolm Scoble (left) says that the collection is an outstanding scientific resource, documenting sites that no longer exist in pristine condition. A trust fund is planned to allow young Japanese researchers to study at the museum.

Ian Mundell

Super JANET. In the same way that Super JANET is intended to improve access to distant academic resources, adding industry should facilitate collaborations. Initially, only companies with active collaborations with university groups will be allowed to join, and no more than 20 per cent of UKERNA's income is supposed to come from industry to ensure that the network continues to serve academics.

Ian Mundell

\section{Russians reject plan for elite research centres}

Moscow. The Russian Academy of Sciences has rejected a proposal by the government to pool its research funds and create a network of well-funded scientific centres. The proposal was intended to ensure that a core of world-class researchers receive sufficient funding to maintain their laboratories even in the face of the current economic crisis. But academicians, after five hours of heated debate, withheld their support out of concern that such a shift in funding would cripple existing institutes and jeopardize their status.

The idea was presented by Boris Saltykov, minister of science, to the academy's presidium at a meeting on 15 September. Institutes designed as federal centres would receive modern equipment, a steady flow of current publications and the opportunity to travel regularly.

It would cost an estimated 1 million rubles to support the work of each researcher at a federal centre, with the money coming from reallocating the present budget. Saltykov believes that several thousand researchers could be supported at that level without robbing the rest of the scientific community of needed resources.

The proposal grows out of a recognition by the scientific community that Russia can no longer afford a system characterized by huge institutions and low scientific productivity. However, the presidium's vote demonstrates that change will not come easily. Its opposition reflects a feeling that such a parallel system of centres may undermine the academy's authority, if not its reputation.

At the same time, most academicians acknowledge that some new structure is needed. One compromise may be to allow the academy to take the lead, designating institutes to be selected as centres and deciding what privileges they will be granted.

Vladimir Pokrowsky 